\title{
A new species of Acanthochondria (Copepoda: Chondracanthidae) parasitizing the flounder Xystreurys rasile (Pleuronectiformes: Paralichthyidae) from Argentina
}

\author{
Ana Julia Alarcos ${ }^{1,2}$ and Juan Tomás Timi ${ }^{1,2}$ \\ ${ }^{1}$ Laboratorio de Parasitología, Departamento de Biología, Facultad de Ciencias Exactas y Naturales, Universidad Nacional de Mar \\ del Plata, Funes 3350, (7600) Mar del Plata, Argentina; \\ ${ }^{2}$ Consejo Nacional de Investigaciones Científicas y Técnicas (CONICET)
}

\begin{abstract}
A new copepod species, Acanthochondria sagitta sp. n., is described based on specimens collected from the flounder Xystreurys rasile (Jordan) (Pleuronectiformes, Paralichthyidae), caught in the coastal waters off Necochea, Buenos Aires Province, Argentina. The new species differs from its congeners by the following combination of characters: presence of three pairs of cephalic outgrowths; the triangular shape of the trunk with diverging postero-lateral processes; leg 2 of an intermediate shape between Types $\mathrm{C}$ and $\mathrm{D}$, which projects laterally from the trunk, and Type B-V antennule bearing two proximal processes (one ventral and one dorsal) on the swollen basal portion.
\end{abstract}

Keywords: parasitic copepod, Acanthochondria sagitta, flounder, Xystreurys rasile, Argentina

The flounder Xystreurys rasile (Jordan) (Pleuronectiformes, Paralichthyidae) is distributed from southern Brazil to San Jorge Gulf in Argentinean waters at depths not exceeding $150 \mathrm{~m}$ (Cousseau and Perrota 2004). In Argentinean waters this species is commercially exploited, constituting one of the main resources among the species caught by the flatfish fishery (Fabré et al. 2001). Despite their economic importance in the regional fisheries, the parasite fauna of $X$. rasile has been little studied. At present only endohelminths (trematodes, nematodes and cestodes) have been recorded in specimens from Argentina (Szidat 1961); however, no records of parasitic copepods have been so far reported for this species.

As a result of a parasitological study carried out on $X$. rasile caught in the waters off Necochea, Argentina, copepods referable to the genus Acanthochondria Oakley, 1927 were found. These copepods represented a new species, which is herein described.

\section{MATERIALS AND METHODS}

A total of 130 specimens of the flounder $X$. rasile, captured in coastal waters off Necochea $\left(38^{\circ} 36^{\prime} \mathrm{S}, 58^{\circ} 42^{\prime} \mathrm{W}\right)$ during December 2009, were examined for parasitic copepods. The parasites were removed from the gill arches, fixed in $4 \%$ formaldehyde and stored in $70 \%$ ethanol. Copepod specimens were studied, both entire and dissected after being cleared in lactic acid, under a light microscope. Illustrations were made using a drawing tube. Measurements (mean followed by the range in parentheses) are given in millimetres. The morphological terminology and the criteria for identifying the new species follow Ho and Kim (1995) and Kalman (2003).

\section{RESULTS}

Acanthochondria sagitta sp.n.

Figs. 1-28

Female (Figs. 1-16): Measurements based on 5 specimens. Body divided into head, short neck, and robust trunk (Figs. 1, 2). Total body length (from anterior margin of head to distal end of posterior processes of trunk) 3.85 (3.38-4.46). Head slightly wider than long, 1.59 (1.40-1.70) long and 1.84 (1.66-2.01) wide, bearing median longitudinal sclerotized bar and 3 lateral pairs of rounded outgrowths (1 antero-dorsal, 1 mid-ventral and 1 postero-dorsal). Trunk robust, arrowhead-shaped, indistinguishably fused to neck, longer than wide, 3.16 (2.83-3.47) long and 1.84 (1.55-2.11) wide at mid-length and postero-laterally extended into two divergent lobes, each extending beyond the genito-abdomen (Figs. 1, 2). Genital complex conical, $0.39(0.39-0.41)$ long and 0.34 (0.26-0.41) wide, arising from postero-dorsal surface of trunk. Abdomen globular, small, broadly fused with genital complex, carrying pair of dorsal setules (Fig. 3). Caudal ramus spiniform, armed with 3 setae (1 dorsolateral and 2 ventral); usual small inner rounded knob not 

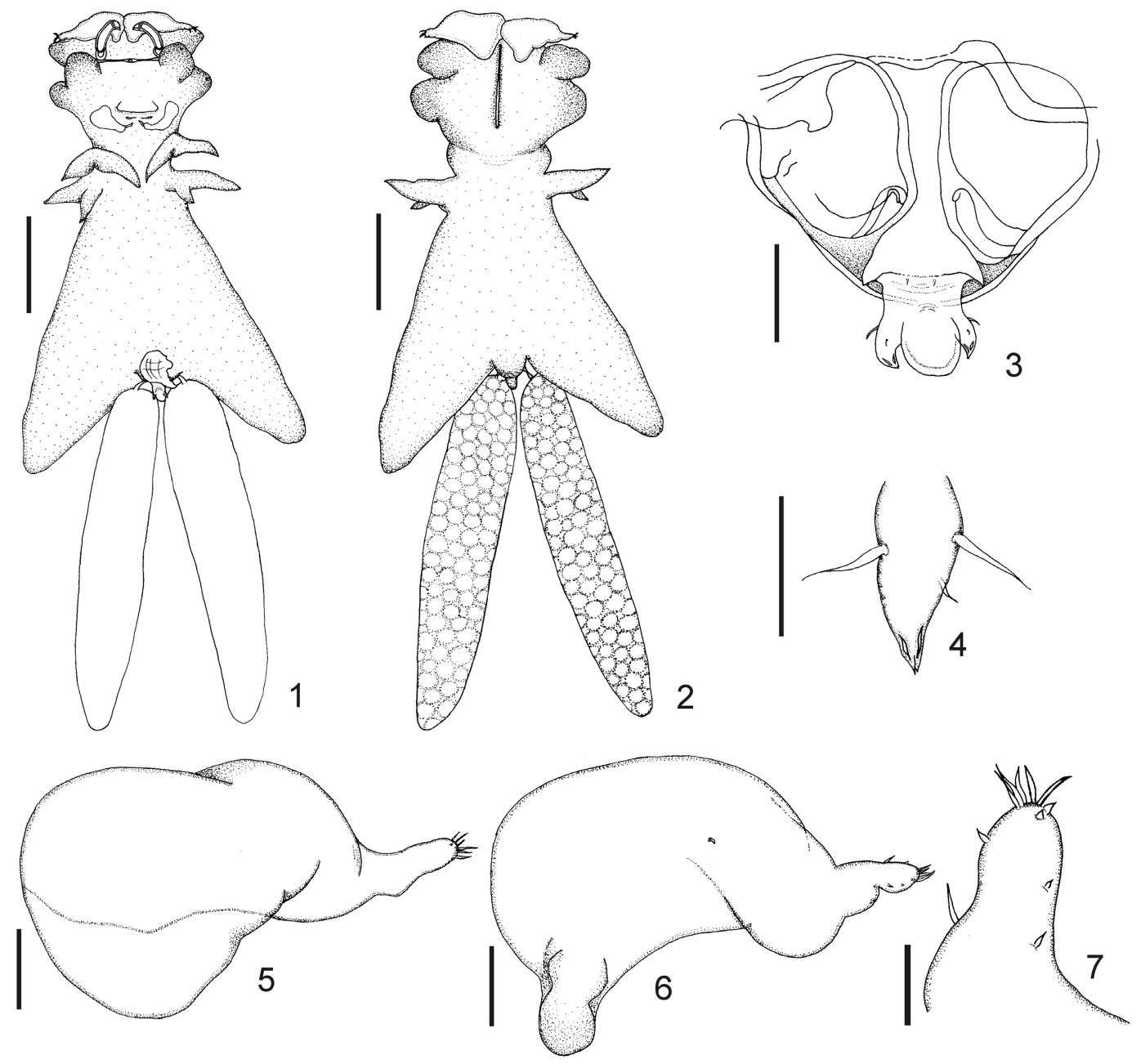

Figs. 1-7. Acanthochondria sagitta sp. n., female. Fig. 1. Habitus, ventral view. Fig. 2. Habitus, dorsal view. Fig. 3. Genito-abdomen, ventral view. Fig. 4. Caudal ramus, ventral view. Fig. 5. Antennule, dorsal view. Fig. 6. Antennule, ventral view. Fig. 7. Antennule (detail of tip), ventral view. Scale bars: Figs. 1, $2=1 \mathrm{~mm}$; Figs. 3, 5, 6=0.125 mm; Figs. 4, $7=0.05 \mathrm{~mm}$.

observed (Fig. 4). Egg sacs cylindrical, multiseriate, 3.85 (3.41-4.49) long and $0.58(0.52-0.71)$ wide.

Antennule (Figs. 5-7) of Type B-V, consisting of a large fleshy base with small seta, and a small cylindrical distal portion armed with 2 ventral and 2 dorsal subapical elements and tipped with 5 naked setae and 2 spines. Swollen basal portion with two basal processes, 1 ventral blunt lobe and 1 dorsal triangular expansion; latter overlays anterior region of head. Antenna (Fig. 8) 2-segmented; terminal segment an uncinate claw with striated ring near tip. Labrum (Fig. 9) naked. Mandible (Fig. 10) with 123-125 minute teeth along convex margin and 68-70 teeth along concave margin of terminal blade. Paragnath a small fleshy lobe armed distally with spinules. Maxillule (Fig. 11) small, lobate, tipped with 2 unequal apical elements and small outer knob. Maxilla (Fig. 12) 2-segmented; first segment robust and unarmed; second segment armed with 2 basal setae and row of 11-13 teeth on inner edge of terminal process. Maxilliped (Figs. 13, 14) 3-segmented; first segment robust and unarmed; second segment with lobate distal end bearing patch of spinules on inner edge; terminal segment small, claw-like, with 1 denticle at distal third of concave side (two denticle rows, each with two to three denticles, were observed in some specimens). Two pairs of biramous legs present, both similar in size, but rami in leg 1 broader than in leg 2 . Leg 1 (Fig. 15) bilobed, situated on neck; protopod bearing outer seta; rami conical, with exopod slightly larger than endopod. Leg 2 (Fig. 16) of an intermediate shape between Types $\mathrm{C}$ and $\mathrm{D}$, situated laterally near junction between neck and trunk; protopod with small outer seta and both rami with sparse spinules on outer edge.

Male (Figs. 17-28): Measurements based on 4 specimens. Body $0.58(0.50-0.71)$ long and 0.32 (0.29-0.38) wide; cephalothorax globose, comprising more than half of total body length; metamerism of body indistinct. Main body flexure located between pedigerous somites 1 and 2 (Fig. 17). Genital complex (Fig. 18) with pair of ventral ridges representing opercula of genital apertures. Abdomen broadly fused with genital complex and indistinct. 

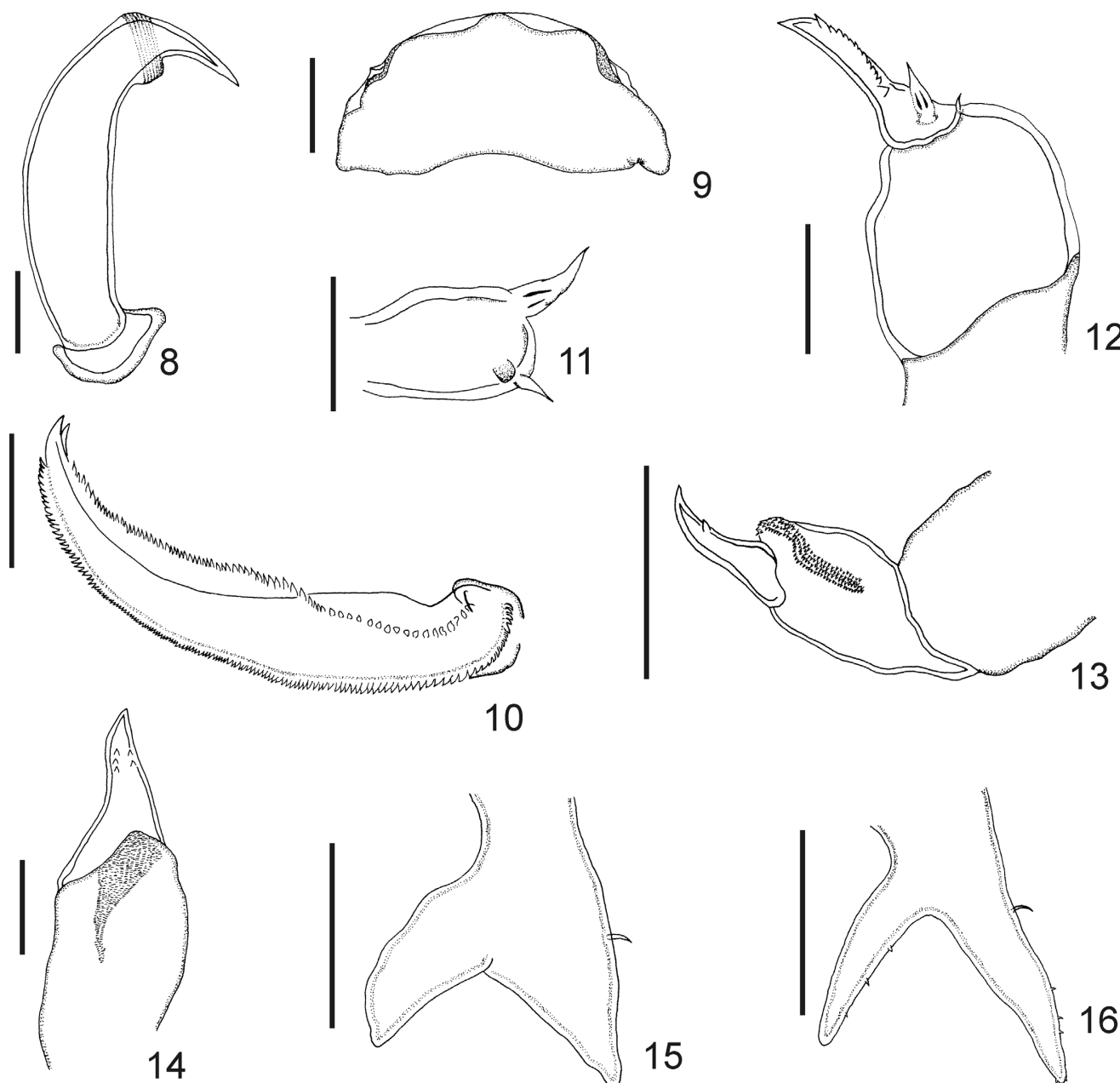

10

14

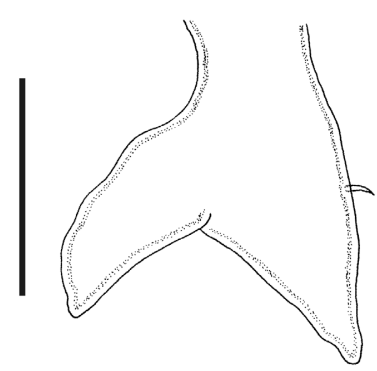

15

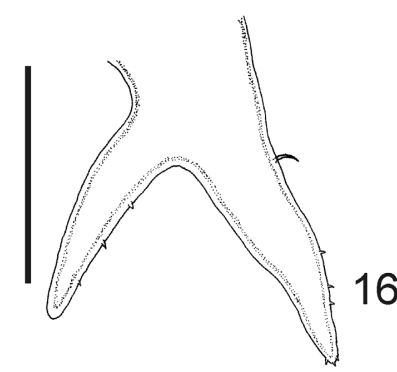

Figs. 8-16. Acanthochondria sagitta sp.n., female. Fig. 8. Antenna. Fig. 9. Labrum. Fig. 10. Mandible. Fig. 11. Maxillule. Fig. 12. Maxilla. Fig. 13. Maxilliped, ventral view. Fig. 14. Maxilliped, dorsal view. Fig. 15. Leg 1. Fig. 16. Leg 2. Scale bars: Fig. $8=0.1 \mathrm{~mm}$; Figs. 9, $13=0.125 \mathrm{~mm}$; Figs. 10, 11, $14=0.05 \mathrm{~mm}$; Fig. $12=0.075 \mathrm{~mm}$; Figs. $15,16=0.5 \mathrm{~mm}$.

Caudal rami (Fig. 19) spiniform, with an attenuated accessory process at tip and 3 basal setules (1 dorsal and 2 ventro-lateral). Antennule (Fig. 20), cylindrical, unmodified, with armature of 2 short proximo-lateral setae, 3 subterminal setae ( 1 long and 2 short) and 9 apical setae (7 long and 2 short). Antenna (Fig. 21) 2-segmented, short and stout; both segments unarmed, claw uncinate. Labrum (Fig. 22) naked. Mandible (Fig. 23), with 45-53 teeth along convex margin and 19-21 teeth along concave margin of terminal blade. Paragnath a small lobe with patch of spinules at tip. Maxillule (Fig. 24) a small naked lobe bearing 2 unequal elements and small outer knob. Maxilla (Fig. 25) as in female, except without teeth on terminal process. Maxilliped (Fig. 26) 3-segmented; first segment robust and unarmed; second segment with lobate distal end bearing spinules on inner edge; terminal segment a small claw with 1 denticle on concave side. Two pairs of reduced biramous legs present (Figs. 27, 28), both lobate and similar in shape; leg 2 smaller than leg 1; protopod bearing 1 large outer seta; exopod tipped with 3-4 setae in leg 1 and 3-5 setae in leg 2; endopod small and conical, with additional small knob in leg 1 .

Ty p e h o st: Flounder, Xystreurys rasile (Jordan) (Pleuronectiformes, Paralichthyidae).

Type locality: Coastal waters off Necochea $\left(38^{\circ} 36^{\prime} \mathrm{S}\right.$, $\left.58^{\circ} 42^{\prime} \mathrm{W}\right)$, Argentina. Date of collection: December 2009.

Site of infection: Gill rakers.

Prevalence : $6.9 \%$ (9 fish infected of 130 examined).

Mean intensity and range: $1.2(1-2)$.

Material deposited: Holotype, No. 26.558 (female); allotype, No. 26.559 (male), and paratypes No. 26.560 (2 females each with attached male) are deposited in the Carcinological Collection of the Museo de La Plata (CHMLP), La Plata, Argentina. Two additional paratypes (female with attached male) are deposited in the Institute of Parasitology, Academy of Sciences of the Czech Republic, České Budějovice, Czech Republic (Cat. No. Cr-12).

E ty mology: The specific name (noun in apposition) is from Latin $($ sagitta, fem. $=$ arrow) and refers to the arrowhead shape of the adult female. 

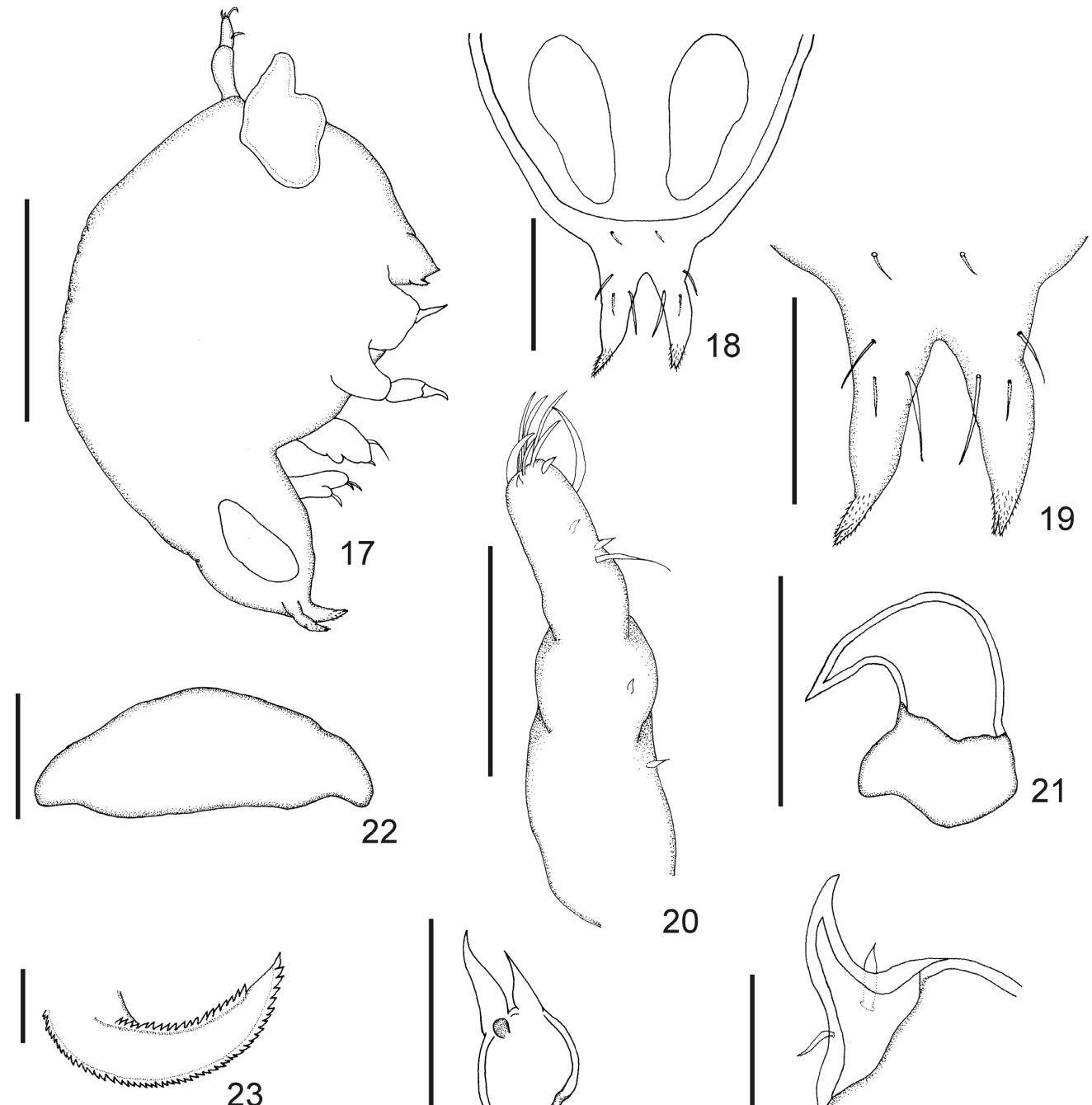

22
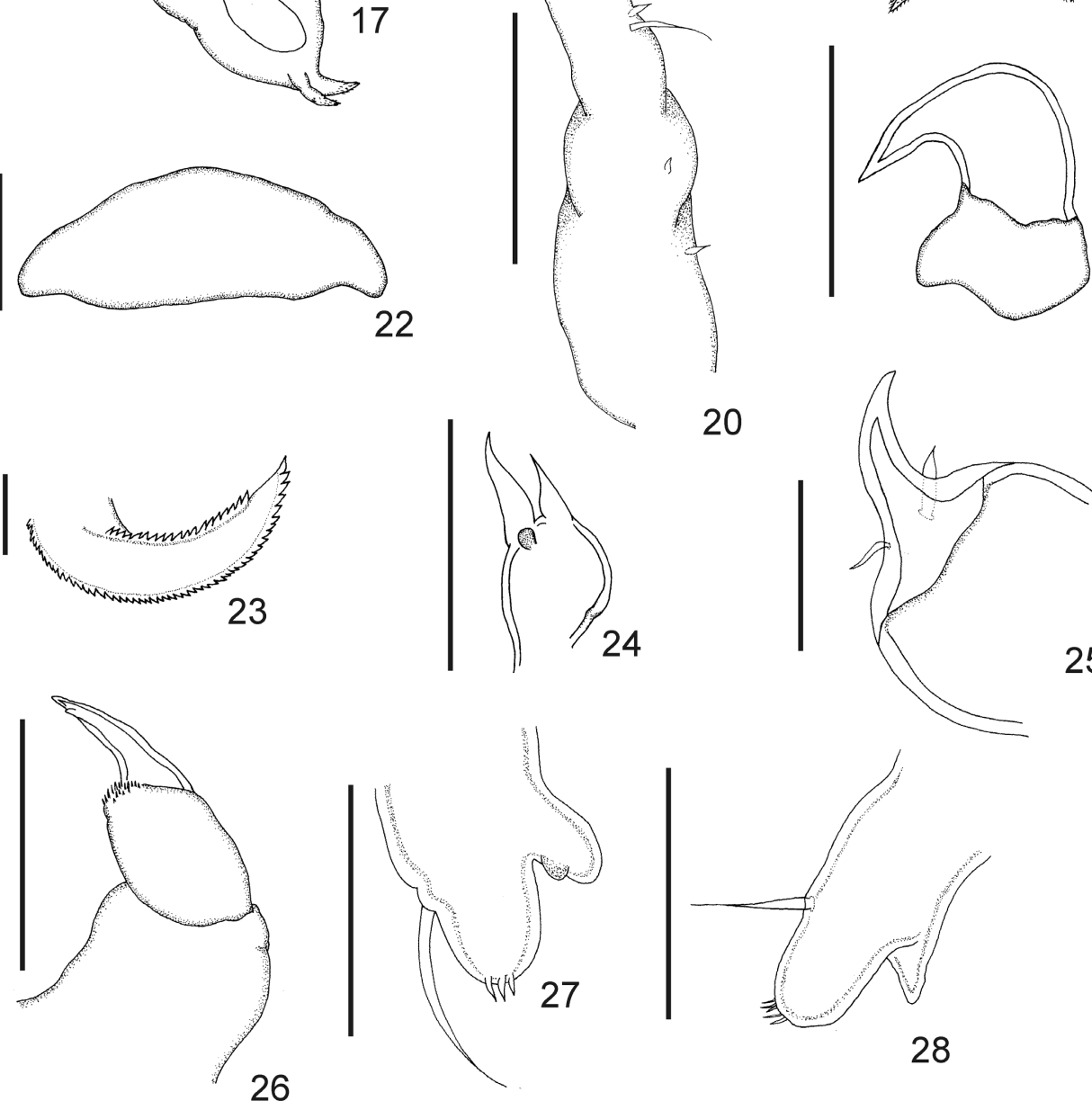

25

Figs. 17-28. Acanthochondria sagitta sp.n., male. Fig. 17. Habitus, lateral view. Fig. 18. Genito-abdomen, ventral view. Fig. 19. Caudal ramus, ventral view. Fig. 20. Antennule. Fig. 21. Antenna. Fig. 22. Labrum. Fig. 23. Mandible. Fig. 24. Maxillule. Fig. 25. Maxilla. Fig. 26. Maxilliped. Fig. 27. Leg 1. Fig. 28. Leg 2. Scale bars: Fig. $17=0.25$ mm; Fig. $18=0.075$ mm; Figs. 19-22, $24-28=0.05 \mathrm{~mm}$; Fig. $23=0.01 \mathrm{~mm}$.

Remarks. Acanthochondria Oakley, 1927 comprises at present 48 valid species, constituting the largest genus of the family Chondracanthidae Milne Edwards, 1840 (see Østergaard 2003, Alves et al. 2003, Braicovich and Timi 2009). The latest review of this genus, with a key to 46 valid species, was provided by Kalman (2003), and it was based on the previous key by Ho and Kim (1995). Two additional species were added after Kalman (2003), namely A. triangularis Alves, Luque et Paraguassu, 2003 and A. serrani Braicovich et Timi, 2009 (Alves et al. 2003, Braicovich and Timi 2009). 
By having a short neck comprising the first and second pedigers, the new species resembles most of species in the genus; however, it can be distinguished from the majority of them by the presence of head outgrowths (in the form of processes, knobs or protrusions). The presence of cephalic outgrowths is one of the characteristics of the genus (Ho 1970); however, these structures are present in a small number of species. In fact, among species of Acanthochondria with a short neck, head outgrowths have been described in A. cornuta (Müller, 1776), A. soleae (Krøyer, 1838), A. clavata (Bassett-Smith, 1896), A. rectangularis (Fraser, 1920), A. pingi (Yü et Wu, 1932), A. bicornis Shiino, 1955, A. brevicorpa Yü, 1935, A. fraseri Ho, 1972, A. priacanthi Shiino, 1964, A. macrocephala Gusev, 1951, A. sicyasis (Krøyer, 1863) and A. zebriae Ho, Kim et Kumar, 2000 (Yü and Wu 1932, Ho 1970, Kabata 1979, 1984). However, the new species is readily distinguished from all of them by having three pairs of cephalic outgrowths rather than one, two or four pairs. The single pair of cephalic outgrowths is situated on the antero-lateral corners of the head for A. bicornis, A. fraseri, A. zebriae, A. pingi, A. cornuta and A. soleae (Yü and Wu 1932, Shiino 1955, Ho 1970, 1972, Kabata 1979, Ho et al. 2000) and in the postero-lateral corner in A. brevicorpa and $A$. priacanthi (Yü 1935, Ho and Kim 1995). The cephalic outgrowths as described by Yü (1935) and Ho and Kim (1995), respectively, in the latter two species may in fact merely represent the swollen oral area typical of chondracanthids rather than true outgrowths. On the other hand, A. sicyasis, A. macrocephala and A. rectangularis possess two pairs: the former species has two lateral protrusions (Ho 1977), the second species with swollen and protruded antero-lateral corners and ventro-lateral portion flanking the oral region (Ho and Kim 1995) and the latter species with two pairs of ventral protrusions (Kabata 1984). Finally, A. clavata possess four pairs of anterolateral cephalic outgrowths (two dorsal and two ventral) (Kabata 1979). Furthermore, the new species also differs from all species in the genus by the following combination of characters: the triangular shape of the trunk with diverging postero-lateral processes; leg 2 of intermediate form between Type $\mathrm{C}$ or $\mathrm{D}$, which projects laterally from the trunk; and the Type B-V antennule with two proximal processes (one ventral and one dorsal) on the swollen basal portion. Males of Acanthochondria do not show species differences (Kalman 2003).

Acknowledgements. The authors wish to thank Mr. Roque Bruno from Santa Cecilia fish market, Necochea, for kindly providing fish samples. Thanks are also due to Gustavo Chiaramonte and to Ricardo Guichón for providing laboratory facilities at the Estación Hidrobiológica at Puerto Quequén and Laboratorio de Ecología Evolutiva Humana belonging to the Unidad de Enseñanza Universitaria Sede Quequén, respectively. Financial support was provided by grants from CONICET (PIP No. 112200801-00024) and ANPCYT (PICT No. 02199).

\section{REFERENCES}

Alves D.R., Luque J.L., Paraguassu A.R. 2003: Acanthochondria triangularis sp.nov. (Copepoda, Poecilostomatoida, Chondracanthidae) parasitic on Urophycis brasiliensis and U. mystaceus (Osteichthyes, Phycidae) from the Southern Brazilian coastal zone. Acta Parasitol. 48: 19-23.

Braicovich P.E., Timi J.T. 2009: Acanthochondria serrani sp. n. (Copepoda: Chondracanthidae) parasitic on Serranus auriga (Perciformes: Serranidae) from Argentinean waters. Folia Parasitol. 56: 313-316.

Cousseau M.B., Perrota R.G. 2004: Peces Marinos de Argentina: Biología, Distribución, Pesca. INIDEP, Mar del Plata, 167 pp.

Fabré N.N., Cousseau M.B., Denegri M.A. 2001: Aspectos de la dinámica poblacional del lenguado Xystreurys rasile (Jordan, 1890) en el sector del Atlántico Sudoccidental comprendido entre $34^{\circ}$ y $40^{\circ} \mathrm{S}$. Invest. Mar. 29: 83-105.

Ho J.S. 1970: Revision of the genera of the Chondracanthidae, a copepod family parasitic on marine fishes. Beaufortia 229: $105-218$.

Ho J.S. 1972: Four new parasitic copepods of the family Chondracanthidae from California inshore fishes. Proc. Biol. Soc. Wash. 85: 523-539.

Ho J.S. 1977: Parasitic copepods of the family Chondracanthidae from fishes of the south-eastern Pacific (Crustacea, Copepoda). Steenstrupia 4: 157-165.

Ho J.S., KIm I.H. 1995: Acanthochondria (Copepoda: Chondracanthidae) parasitic on fishes of Sado Island in the Sea of Japan, with a preliminary review of the genus. Rep. Sado Mar. Biol. Stn. Niigata Univ. 25: 45-67.
Ho J.S., Kim I.H., Kumar A.B. 2000: Chondracanthid copepods parasitic on flatfishes of Kerala, India. J. Nat. Hist. 34: 709-735.

Kabata Z. 1979: Parasitic Copepoda of British Fishes. The Ray Society, London, 468 pp.

KaвAтA Z. 1984: A contribution to the knowledge of Chondracanthidae (Copepoda: Poecilostomatoida) parasitic on fishes of British Columbia. Can. J. Zool. 62: 1703-1713.

Kalman J.E. 2003: Acanthochondria hoi, a new species of parasitic copepod (Poecilostomatoida: Chondracanthidae) on the California halibut, Paralichthys californicus, from Santa Monica Bay, California, with an amended key to the genus Acanthochondria. Proc. Biol. Soc. Wash. 116: 811-819.

ØStergaARd P. 2003: Catalogue of genera and species of the family Chondracanthidae Milne Edwards, 1840 (Copepoda: Poecilostomatoida) with notes on morphology. Syst. Parasitol. 55: $135-150$.

Shinno S.M. 1955: Copepods parasitic on Japanese fishes, 9. Family Chondracanthidae, subfamily Chondracanthinae. Rep. Fac. Fish., Pref. Univ. Mie 2: 70-111.

SzIDAT L. 1961: Versuch einer Zoogeographie des Süd-Atlantik mit Hilfe von Leitparasiten der Meeresfische. Parasitol. Schrift. 13: $1-98$.

YÜ S.C. 1935: Studies on the parasitic copepods of China belonging to the family Chondracanthidae. Bull. Fan Mem. Inst. Biol. 6: $1-15$.

YÜ S.C., Wu H.W. 1932: Parasitic copepods of the flatfishes from China. Bull. Fan Mem. Inst. Biol. 3: 55-75. 